\title{
PENGARUH BOREDOM PRONENESS DAN LOCUS OF CONTROL TERHADAP KECEPATAN SAAT MENGEMUDI DI JABODETABEK
}

\author{
Gavriel Ganesia ${ }^{1}$ dan Leksmono Suryo Putranto ${ }^{2}$ \\ ${ }^{1}$ Program Studi Sarjana Teknik Sipil, Universitas Tarumanagara, Jl. Letjen S. Parman No.1 Jakarta \\ gavriel.325150107@stu.untar.ac.id \\ ${ }^{2}$ Program Studi Sarjana Teknik Sipil, Universitas Tarumanagara, Jl. Letjen S. Parman No.1 Jakarta \\ leksmonop@ft.untar.ac.id
}

Masuk: 10-01-2021, revisi: 11-04-2021, diterima untuk diterbitkan: 12-04-2021

\begin{abstract}
Driving is an activity that contains a high risk such as loss, damage, loss, accidents and even death, so the drivers requires full attention with very high concentration. One of the causes of accidents experienced by some drivers is the result of several internal factors from the driver, one of the factors is boredom proneness. To be able to control all factors while driving, of course, good control skills are needed for the driver. One of the constructs that is able to explain this is the locus of control. In terms of driving on the road, drivers must also pay attention to personal safety by paying attention to vehicle speed. This research was conducted to determine the effect of locus control on boredom prone, boredom prone to speed, and control locus on speed. Data for research were obtained through online questionnaires. This research will be the method of Structural Equation Modeling (SEM). From the research results, it was found that the boredom proneness greatly affects a person's choice of speed. Meanwhile, the locus of control is a factor that slightly affects a person's speed selection. In addition, the locus of control is sufficient to affect a person's boredom proneness nature
\end{abstract}

Keywords: Boredom Proneness; Locus of Control; Speeding; Structure Equation Modeling

\section{ABSTRAK}

Mengemudi merupakan kegiatan yang mengandung resiko tinggi seperti kerugian, kerusakan, kehilangan, kecelakaan bahkan kematian, dengan demikian pengemudi membutuhkan perhatian penuh dengan konsentrasi sangat tinggi. Salah satu penyebab kecelakaan yang dialami beberapa pengemudi adalah akibat beberapa faktor internal dari pengemudi tersebut, salah satu faktor nya adalah rawan bosan. Untuk dapat mengontrol semua faktor ketika mengemudi, tentu dibutuhkan kemampuan kontrol yang baik pada pengemudi. Salah satu konstruk yang mampu menjelaskan hal tersebut yaitu lokus kendali. Dalam hal mengemudi di jalan, pengemudi juga harus memperhatikan keselamatan diri dengan memperhatikan kecepatan kendaraan. Penelitian ini dilakukan untuk mengetahui pengaruh lokus kendali terhadap rawan bosan, rawan bosan terhadap kecepatan, dan lokus kendali terhadap kecepatan. Data untuk penelitian didapatkan melalui kuesioner secara online. Penelitian ini akan Metode Structural Equation Modeling (SEM). Dari hasil penelitian didapatkan bahwa rawan bosan sangat mempengaruhi pilihan kecepatan seseorang. Sedangkan lokus kendali merupakan faktor yang sedikit mempengaruhi pemilihan kecepatan seseorang. Selain itu lokus kendali cukup mempengaruhi sifat rawan bosan seseorang.

Kata Kunci: Rawan Bosan; Lokus Kendali; Kecepatan; Structure Equation Modeling

\section{PENDAHULUAN}

Menurut UU No 22 Tahun 2009 pasal 1 tentang Lalu Lintas dan Angkutan Jalan, pengemudi adalah orang yang mengemudikan kendaraan bermotor di jalan yang memiliki surat izin mengemudi. Mengemudi sebenarnya merupakan kegiatan yang mengandung resiko tinggi seperti kerugian, kerusakan, kehilangan, kecelakaan bahkan kematian, dengan demikian pekerjaan mengemudi membutuhkan konsentrasi tinggi. Salah satu penyebab kecalakaan yang dialami beberapa pengemudi adalah akibat beberapa faktor internal dari pengemudi tersebut, salah satu faktor nya adalah boredom proneness. Boredom proneness dapat mengubah mood seseorang pada saat megemudi. Boredom proneness juga dapat menyebabkan rasa kantuk yang dialami oleh beberapa pengemudi yang mengakibatkan kecelakaan fatal saat sedang berkendara. Dalam Bustan (2007), ada 5 faktor yang berkaitan dengan peristiwa kecelakaan lalu lintas, yaitu faktor pengemudi, penumpang, pemakai jalan, kendaraan, dan fasilitas jalanan. Untuk dapat mengontrol semua faktor tersebut ketika mngemudi, tentu dibutuhkan kemampuan kontrol yang baik pada pengendara. Salah satu konstruk yang mampu menjelaskan hal tersebut yaitu locus of control. 
Dalam hal mengemudi di jalan, pengemudi harus memperhatikan keselamatan diri dengan memperhatikan kecepatan kendaraan. Hal tersebut bertujuan bagi pengguna jalan agar terjamin keselamatannya sampai ke tujuan. Sebagai contoh dalam mengemudi, sangat penting untuk mengetahui batas kecepatan minimum dan maksimum kendaraan tersebut agar tidak terjadi hal yang tidak diinginkan (Nurliana \& Supani, 2018). Penelitian ini bertujuan untuk mengetahui pengaruh locus of control terhadap boredom proneness, mengetahui pengaruh boredom proneness terhadap kecepatan, dan mengetahui pengaruh locus of control terhadap kecepatan.

\section{Boredom Proneness}

Boredom proneness dapat diartikan sebagai keadaan gairah dan ketidakpuasan yang relatif rendah dikarenakan situasi yang tidak menstimulasi secara memadai (Vodanovich, 2016). Boredom proneness terbukti memiliki hubungan dengan disfungsi perilaku. Sebagai isu psikologis, boredom proneness telah menjadi permasalahan yang cukup luas dan signifikan.

\section{Locus of Control}

Locus of control adalah cara pandang seseorang terhadap suatu peristiwa apakah dia merasa dapat atau tidak dapat mengendalikan peristiwa yang terjadi padanya (Rotter, 1966 dalam Ayudiati, 2010). Locus of control terbagi menjadi dua macam yaitu locus of control internal dan locus of control eksternal. Menurut Kreitner \& Kinicki (2009) individu yang memiliki kecendrungan locus of control internal adalah individu yang memiliki keyakinan untuk dapat mengendalikan segala peristiwa dan konsekuensi yang memberikan dampak pada hidup mereka. Sedangkan locus of control eksternal adalah individu yang memiliki keyakinan bahwa kinerja adalah hasil dari peristiwa di luar kendali langsung mereka.

\section{Kecepatan}

Menurut Julianto (2010), kecepatan merupakan parameter utama selain volume dan kerapatan yang dapat menjelaskan keadaan arus lalu lintas di jalan. Kecepatan dibagi menjadi 3 macam yaitu kecepatan bergerak, kecepatan setempat, dan kecepatan perjalanan. Kecepatan bergerak adalah kecepatan kendaraan rata-rata pada saat kendaraan bergerak yang didapatkan dengan membagi panjang jalur yang ditempuh dengan waktu kendaraan bergerak pada suatu ruas jalan. Kecepatan setempat adalah yaitu kecepatan kendaraan yang diukur dari suatu tempat yang telah ditentukan. Kecepatan perjalanan adalah kecepatan efektif kendaraan yang sedang dalam perjalanan antara dua tempat

\section{METODE PENELITIAN}

Metode pengumpulan data yang digunakan dalam penelitian ini adalah dengan melakukan penyebaran kuesioner secara online. Penelitian ini dimulai dari identifikasi masalah dan penentuan tujuan dari penelitian ini, studi literatur. Tahap selanjutnya adalah rumusan dan ruang lingkup penelitian. Ruang lingkup dalam penelitian ini terdiri dari subjek penelitian, lokasi penelitian dan data penelitian. Batasan penelitian berupa responden yang tinggal dan di daerah Jabodetabek dan sudah memiliki SIM A. Setelah tahap tersebut maka akan melanjutkan ke tahap penyusunan kuesioner. Skala Likert terdiri dari empat pernyataan sikap yaitu Sangat Tidak Setuju (STS) yang berbobot nilai 1, Tidak Setuju (TS) yang berbobot nilai 2, Setuju (S) yang berbobot nilai 3, Sangat Setuju (SS) yang berbobot nilai 4. Setelah kuesioner disebarkan akan dilakukan uji validitas dan uji reliabilitas dengan program SPSS untuk mengetahui apakah kuesioner yang telah dibuat dapat dinyatakan valid dan reliabel. Setelah mendapatkan hasil dari uji validitas dan reliabilitas, maka dilakukan perbaikan kalimat pada indikator pertanyaan yang hasilnya tidak valid dan tidak reliabel. Setelah melalui tahap penyempurnaan kuesioner maka dilakukan analisis data menggunakan program AMOS dengan menggunakan metode Structural Equation Modelling (SEM) dan menentukan kesimpulan dan saran.

\section{HASIL DAN PEMBAHASAN}

Pada awal perencanaan dilakukan penyebaran kuesioner dengan target sebesar 150 responden. Daftar pertanyaan yang disajikan pada kuesioner yang disebarkan meliputi 3 bagian yaitu pencarian sensasi, locus of control dan pilihan kecepatan saat mengemudi. Daftar pertayaan kuesioner dapat dilihat dalam tabel 1. 
Tabel 1. Daftar pertanyaan kuesioner

\begin{tabular}{|c|c|c|}
\hline Bagian & No & Pertanyaan \\
\hline \multirow{18}{*}{$\begin{array}{l}\text { Boredom } \\
\text { Proneness }\end{array}$} & bp1 & Ketika bekerja saya sering merasa diri saya mengkhawatirkan hal- hal lain \\
\hline & bp2 & $\begin{array}{l}\text { Dibutuhkan lebih banyak stimulasi (dorongan) untuk membuat saya maju daripada orang } \\
\text { lain }\end{array}$ \\
\hline & bp3 & $\begin{array}{l}\text { Saya sering menemukan diri saya mengalami "jalan buntu" dan tidak tahu apa yang harus } \\
\text { dilakukan }\end{array}$ \\
\hline & bp4 & $\begin{array}{l}\text { Saya sering terjebak pada situasi dimana saya melakukan hal-hal yang tidak } \\
\text { bermakna }\end{array}$ \\
\hline & bp5 & Melihat video rumah atau foto perjalanan seseorang membuat saya sangat bosan \\
\hline & bp6 & Hal-hal yang saya lakukan bersifat berulang-ulang dan monoton \\
\hline & bp7 & Waktu sepertinya berlalu sangat lambat \\
\hline & bp8 & Saya jarang bersemangat jika melakukan pekerjaan saya \\
\hline & bp9 & Sebagian besar waktu saya hanya duduk-duduk tanpa melakukan apapun \\
\hline & bp 10 & Saya sering menemukan diri saya tanpa ada waktu luang di tangan saya \\
\hline & bp11 & Dalam situasi di mana saya harus menunggu, seperti antrian, saya menjadi sangat gelisah \\
\hline & bp12 & Akan sangat sulit bagi saya untuk menemukan pekerjaan yang cukup menarik \\
\hline & bp13 & Saya merasa bahwa saya bekerja di bawah kemampuan saya hampir sepanjang waktu \\
\hline & bp14 & $\begin{array}{l}\text { Kecuali jika saya melakukan sesuatu yang menarik, bahkan berbahaya, saya merasa } \\
\text { setengah mati dan membosankan }\end{array}$ \\
\hline & bp15 & Butuh banyak perubahan dan variasi untuk membuat saya benar-benar bahagia \\
\hline & bp16 & $\begin{array}{l}\text { Tampaknya hal yang sama dalam televisi atau film sepanjang waktu, sungguh } \\
\text { membosankan }\end{array}$ \\
\hline & bp17 & Ketika saya masih muda, saya sering berada dalam situasi yang monoton dan melelahkan \\
\hline & bp18 & Di antara teman-teman saya, saya yang terus melakukan sesuatu paling lambat \\
\hline \multirow{3}{*}{$\begin{array}{l}\text { Locus of } \\
\text { Control }\end{array}$} & lc1 & $\begin{array}{l}\text { Saya percaya bahwa ketika saya membuat kesalahan, saya dapat memperbaiki atas } \\
\text { kesalahan yang saya lakukan }\end{array}$ \\
\hline & lc2 & $\begin{array}{l}\text { Saya percaya bahwa cara terbaik untuk menangani masalah adalah dengan tidak } \\
\text { memikirkan masalah tersebut }\end{array}$ \\
\hline & $1 \mathrm{c} 3$ & Saya percaya bahwa hidup saya ditentukan oleh saya sendiri \\
\hline
\end{tabular}


Tabel 1. Daftar pertanyaan kuesioner (Lanjutan)

\begin{tabular}{|c|c|c|}
\hline Bagian & No & Pertanyaan \\
\hline \multirow{10}{*}{$\begin{array}{l}\text { Lotus of } \\
\text { Control }\end{array}$} & lc4 & Saya percaya bahwa saya tidak dapat menentukan apa yang dapat terjadi di hidup saya \\
\hline & lc5 & Ketika saya berusaha untuk melakukan sesuatu, saya pasti mengalami kegagalan \\
\hline & lc6 & $\begin{array}{l}\text { Saya tidak percaya jika berusaha keras dalam melakukan sesuatu akan } \\
\text { mendapatkan hasil yang baik }\end{array}$ \\
\hline & lc7 & Saya percaya ketika saya berusaha, saya akan mendapatkan hal yang saya inginkan \\
\hline & lc8 & $\begin{array}{l}\text { Saya merasa tidak ada gunanya mencoba sesuatu hal karena saya percaya bahwa } \\
\text { saya tidak lebih pintar dari orang lain }\end{array}$ \\
\hline & lc9 & Saya percaya dengan keberuntungan \\
\hline & lc10 & Saya percaya bahwa apa yang terjadi hari ini adalah sesuatu yang tidak disengaja \\
\hline & lc11 & Saya percaya lebih baik menjadi beruntung daripada menjadi pintar \\
\hline & lc12 & Saya adalah orang yang membutuhkan bantuan orang lain ketika mengerjakan sesuatu \\
\hline & lc13 & Sebagian dari hidup saya dipengaruhi oleh orang lain \\
\hline \multirow{4}{*}{$\begin{array}{l}\text { Pilihan } \\
\text { Kecepatan Saat } \\
\text { Mengemudi }\end{array}$} & $\mathrm{k} 1$ & Saya sering berkendara dengan kecepatan tinggi ketika jalan sedang sepi \\
\hline & $\mathrm{k} 2$ & $\begin{array}{l}\text { Saya tidak suka mengemudi dengan kecepatan tinggi ketika melewati } \\
\text { kawasan permukiman }\end{array}$ \\
\hline & $\mathrm{k} 3$ & Saya tidak suka mengemudi dengan kecepatan tinggi di tikungan \\
\hline & $\mathrm{k} 4$ & Saya sering mengemudi dengan kecepatan tinggi ketika kondisi hujan \\
\hline
\end{tabular}

Responden akan menjawab dengan memilih 4 pilihan jawaban yaitu yaitu Sangat Tidak Setuju (STS) yang berbobot nilai 1, Tidak Setuju (TS) yang berbobot nilai 2, Setuju (S) yang berbobot nilai 3, Sangat Setuju (SS) yang berbobot nilai 4. Terdapat juga uji validitas dan uji reliabilitas terhadap pertanyaan di kuesioner ini. Berikut hasil dari uji validitas dan uji reliabilitas terhadap kuesioner ini. Hasil uji validitas dan reabilitas dapat dilihat dalam tabel 2. 
Tabel 2. Hasil uji validitas dan reabilitas

\begin{tabular}{|c|c|c|c|}
\hline No & Pertanyaan & Kriteria & Nilai Cronbach's Alpha \\
\hline & & & 0,845 \\
\hline 1 & $\begin{array}{l}\text { Ketika bekerja saya sering merasa diri saya mengkhawatirkan } \\
\text { hal- hal lain }\end{array}$ & Valid & \\
\hline 2 & $\begin{array}{l}\text { Dibutuhkan lebih banyak stimulasi (dorongan) untuk } \\
\text { membuat saya maju daripada orang lain }\end{array}$ & Valid & \\
\hline 3 & $\begin{array}{l}\text { Saya sering menemukan diri saya mengalami "jalan buntu" } \\
\text { dan tidak tahu apa yang harus dilakukan }\end{array}$ & $\begin{array}{l}\text { Tidak } \\
\text { Valid }\end{array}$ & \\
\hline 4 & $\begin{array}{l}\text { Saya sering terjebak pada situasi dimana saya melakukan hal- } \\
\text { hal yang tidak bermakna }\end{array}$ & Valid & \\
\hline 5 & $\begin{array}{l}\text { Melihat video rumah atau foto perjalanan seseorang membuat } \\
\text { saya sangat bosan }\end{array}$ & Valid & \\
\hline 6 & $\begin{array}{l}\text { Hal-hal yang saya lakukan bersifat berulang-ulang dan } \\
\text { monoton }\end{array}$ & Valid & \\
\hline 7 & Waktu sepertinya berlalu sangat lambat & Valid & \\
\hline 8 & Saya jarang bersemangat jika melakukan pekerjaan saya & Valid & \\
\hline 9 & $\begin{array}{l}\text { Sebagian besar waktu saya hanya duduk-duduk tanpa } \\
\text { melakukan apapun }\end{array}$ & Valid & \\
\hline 10 & $\begin{array}{l}\text { Saya sering menemukan diri saya tanpa ada waktu luang di } \\
\text { tangan saya }\end{array}$ & Valid & \\
\hline 11 & $\begin{array}{l}\text { Dalam situasi di mana saya harus menunggu, seperti antrian, } \\
\text { saya menjadi sangat gelisah }\end{array}$ & Valid & \\
\hline 12 & $\begin{array}{l}\text { Akan sangat sulit bagi saya untuk menemukan pekerjaan } \\
\text { yang cukup menarik }\end{array}$ & Valid & \\
\hline 13 & $\begin{array}{l}\text { Saya merasa bahwa saya bekerja di bawah kemampuan saya } \\
\text { hampir sepanjang waktu }\end{array}$ & Valid & \\
\hline 14 & $\begin{array}{l}\text { Kecuali jika saya melakukan sesuatu yang menarik, bahkan } \\
\text { berbahaya, saya merasa setengah mati dan membosankan }\end{array}$ & Valid & \\
\hline 15 & $\begin{array}{l}\text { Butuh banyak perubahan dan variasi untuk membuat saya } \\
\text { benar-benar bahagia }\end{array}$ & $\begin{array}{l}\text { Tidak } \\
\text { Valid }\end{array}$ & \\
\hline 16 & $\begin{array}{l}\text { Tampaknya hal yang sama dalam televisi atau film } \\
\text { sepanjang waktu, sungguh membosankan }\end{array}$ & Valid & \\
\hline
\end{tabular}


Tabel 2. Hasil uji validitas dan reabilitas (Lanjutan)

\begin{tabular}{llcc}
\hline No & \multicolumn{1}{c}{ Pertanyaan } & Kriteria & Nilai Cronbach's Alpha \\
\hline & \multicolumn{2}{c}{0,845} \\
\hline 17 & $\begin{array}{l}\text { Ketika saya masih muda, saya sering berada dalam situasi } \\
\text { yang monoton dan melelahkan }\end{array}$ & Valid \\
& $\begin{array}{l}\text { Di antara teman-teman saya, saya yang terus melakukan } \\
18\end{array}$ & Valid \\
\hline
\end{tabular}

0,714

\begin{tabular}{|c|c|c|c|}
\hline 19 & Mudah bagi saya untuk berkonsentrasi pada aktivitas saya & Valid & \\
\hline 20 & $\begin{array}{l}\text { Sepanjang waktu saya memproyeksikan dalam pikiran saya } \\
\text { tentang hal-hal yang harus dilakukan }\end{array}$ & Valid & \\
\hline \multirow{2}{*}{21} & \multirow{2}{*}{ Saya merasa mudah untuk menghibur diri sendiri } & Tidak & \\
\hline & & Valid & \\
\hline 22 & Saya mendapat banyak pujian dari apa yang saya lakukan & Valid & \\
\hline 23 & $\begin{array}{l}\text { Didalam kondisi apapun saya terbiasa mencari sesuatu agar } \\
\text { minat saya terjaga }\end{array}$ & Valid & \\
\hline 24 & Saya suka menunggu dengan sabar & Valid & \\
\hline 25 & Saya sering terbangun dengan ide baru & Valid & \\
\hline 26 & $\begin{array}{l}\text { Saya ingin melakukan hal-hal yang lebih menantang dalam } \\
\text { hidup }\end{array}$ & Valid & \\
\hline 27 & $\begin{array}{l}\text { Banyak orang akan mengatakan bahwa saya orang yang } \\
\text { kreatif atau imajinatif }\end{array}$ & Valid & \\
\hline \multirow{3}{*}{28} & Saya memiliki banyak minat, saya tidak punya waktu untuk & Tidak & \\
\hline & melakukan semuanya & Valid & \\
\hline & & & 0,211 \\
\hline 29 & $\begin{array}{l}\text { Saya percaya bahwa ketika saya membuat kesalahan, saya } \\
\text { dapat memperbaiki atas kesalahan yang saya lakukan }\end{array}$ & Valid & \\
\hline 30 & $\begin{array}{l}\text { Saya percaya bahwa cara terbaik untuk menangani masalah } \\
\text { adalah dengan tidak memikirkan masalah tersebut }\end{array}$ & Valid & \\
\hline 31 & Saya percaya bahwa hidup saya ditentukan oleh saya sendiri & Valid & \\
\hline 32 & $\begin{array}{l}\text { Saya percaya bahwa saya tidak dapat menentukan apa yang } \\
\text { dapat terjadi dihidup saya }\end{array}$ & Valid & \\
\hline
\end{tabular}


Tabel 2. Hasil uji validitas dan reabilitas (Lanjutan)

\begin{tabular}{|c|c|c|c|}
\hline No & Pertanyaan & Kriteria & Nilai Cronbach's Alpha \\
\hline & & & 0,195 \\
\hline 33 & $\begin{array}{l}\text { Ketika saya berusaha untuk melakukan sesuatu, saya pasti } \\
\text { mengalami kegagalan }\end{array}$ & Valid & \\
\hline 34 & $\begin{array}{l}\text { Saya tidak percaya jika berusaha keras dalam melakukan } \\
\text { sesuatu akan mendapatkan hasil yang baik }\end{array}$ & Valid & \\
\hline \multirow{2}{*}{35} & Saya percaya ketika saya berusaha, saya akan mendapatkan & Tidak & \\
\hline & hal yang saya inginkan & Valid & \\
\hline \multirow[t]{2}{*}{36} & $\begin{array}{l}\text { Saya merasa tidak ada gunanya mencoba sesuatu hal karena } \\
\text { saya percaya bahwa saya tidak lebih pintar dari orang lain }\end{array}$ & Valid & \\
\hline & & & 0,318 \\
\hline 37 & Saya percaya dengan keberuntungan & Valid & \\
\hline 38 & $\begin{array}{l}\text { Saya percaya bahwa apa yang terjadi hari ini adalah sesuatu } \\
\text { yang tidak disengaja }\end{array}$ & Valid & \\
\hline \multirow[t]{2}{*}{39} & $\begin{array}{l}\text { Saya percaya lebih baik menjadi beruntung daripada menjadi } \\
\text { pintar }\end{array}$ & Valid & \\
\hline & & & 0,393 \\
\hline 40 & $\begin{array}{l}\text { Saya adalah orang yang membutuhkan bantuan orang lain } \\
\text { ketika mengerjakan sesuatu }\end{array}$ & Valid & \\
\hline \multirow[t]{2}{*}{41} & Sebagian dari hidup saya dipengaruhi oleh orang lain & Valid & \\
\hline & & & 0,644 \\
\hline 43 & $\begin{array}{l}\text { Saya sering berkendara dengan kecepatan tinggi ketika jalan } \\
\text { sedang sepi }\end{array}$ & Valid & \\
\hline \multirow[t]{2}{*}{44} & $\begin{array}{l}\text { Saya sering mengemudi dengan kecepatan tinggi ketika } \\
\text { kondisi hujan }\end{array}$ & Valid & \\
\hline & & & 0,613 \\
\hline 45 & $\begin{array}{l}\text { Saya tidak suka mengemudi dengan kecepatan tinggi di } \\
\text { tikungan }\end{array}$ & Valid & \\
\hline 46 & $\begin{array}{l}\text { Saya tidak suka mengemudi dengan kecepatan tinggi ketika } \\
\text { melewati kawasan permukiman }\end{array}$ & Valid & \\
\hline
\end{tabular}

Setelah melakukan uji coba validitas dan reliabilitas, maka peneliti akan menampilkan data hasil dari jawaban responden mengenai. extremely bored, extremely interested, kepercayaan terhadap diri sendiri, kepercayaan terhadap hasil usaha, kepercayaan tentang adanya keberuntungan, ketergantungan akan bantuan orang lain, pilihan kecepatan saat mengemudi (langsung) dan pilihan kecepatan saat mengemudi (tak langsung). Pada tabel 3 akan disertakan tabel mean dengan dimensi extremely bored. 
Tabel 3. Jumlah data $(\mathrm{N})$, frekuensi extremely bored

\begin{tabular}{|c|c|c|c|c|c|c|c|}
\hline \multirow[t]{2}{*}{ NO. } & \multirow[t]{2}{*}{ INDIKATOR } & \multirow[t]{2}{*}{$\mathrm{N}$} & \multicolumn{3}{|c|}{ SKALA } & & \multirow[t]{2}{*}{$M E A N$} \\
\hline & & & 1 & 2 & 3 & 4 & \\
\hline 1 & $\begin{array}{l}\text { Ketika bekerja saya sering merasa diri } \\
\text { saya mengkhawatirkan hal- hal lain }\end{array}$ & 150 & 55 & 38 & 37 & 20 & 2,14 \\
\hline 2 & $\begin{array}{l}\text { Dibutuhkan lebih banyak stimulasi } \\
\text { (dorongan) untuk membuat saya maju } \\
\text { daripada orang lain }\end{array}$ & 150 & 16 & 35 & 68 & 31 & 2,76 \\
\hline 3 & $\begin{array}{l}\text { Saya sering menemukan diri saya } \\
\text { mengalami "jalan buntu" dan tidak tahu } \\
\text { apa yang harus dilakukan }\end{array}$ & 150 & 20 & 83 & 41 & 6 & 2,22 \\
\hline 4 & $\begin{array}{l}\text { Saya sering terjebak pada situasi dimana } \\
\text { saya melakukan hal-hal yang tidak } \\
\text { bermakna }\end{array}$ & 150 & 50 & 46 & 32 & 22 & 2,17 \\
\hline 5 & $\begin{array}{l}\text { Melihat video rumah atau foto perjalanan } \\
\text { seseorang membuat saya sangat bosan }\end{array}$ & 150 & 66 & 50 & 26 & 8 & 1,84 \\
\hline 6 & $\begin{array}{l}\text { Hal-hal yang saya lakukan bersifat } \\
\text { berulang-ulang dan monoton }\end{array}$ & 150 & 10 & 81 & 47 & 12 & 2,40 \\
\hline 7 & Waktu sepertinya berlalu sangat lambat & 150 & 82 & 44 & 23 & 1 & 1,62 \\
\hline 8 & $\begin{array}{l}\text { Saya jarang bersemangat jika melakukan } \\
\text { pekerjaan saya }\end{array}$ & 150 & 29 & 86 & 28 & 7 & 2,08 \\
\hline 9 & $\begin{array}{l}\text { Sebagian besar waktu saya hanya duduk- } \\
\text { duduk tanpa melakukan apapun }\end{array}$ & 150 & 35 & 83 & 27 & 5 & 2,01 \\
\hline 10 & $\begin{array}{l}\text { Saya sering menemukan diri saya tanpa } \\
\text { ada waktu luang di tangan saya }\end{array}$ & 150 & 12 & 90 & 25 & 23 & 2,39 \\
\hline 11 & $\begin{array}{l}\text { Dalam situasi di mana saya harus } \\
\text { menunggu, seperti antrian, saya menjadi } \\
\text { sangat gelisah }\end{array}$ & 150 & 19 & 82 & 32 & 17 & 2,31 \\
\hline 12 & $\begin{array}{l}\text { Akan sangat sulit bagi saya untuk } \\
\text { menemukan pekerjaan yang cukup } \\
\text { menarik }\end{array}$ & 150 & 18 & 82 & 40 & 10 & 2,28 \\
\hline 13 & $\begin{array}{l}\text { Saya merasa bahwa saya bekerja di } \\
\text { bawah kemampuan saya hampir } \\
\text { sepanjang waktu }\end{array}$ & 150 & 18 & 33 & 73 & 26 & 2,71 \\
\hline
\end{tabular}


Tabel 3. Jumlah data (N), frekuensi extremely bored (Lanjutan)

\begin{tabular}{|c|c|c|c|c|c|c|c|}
\hline \multirow[t]{2}{*}{ NO. } & \multirow[t]{2}{*}{ INDIKATOR } & \multirow[t]{2}{*}{$\mathrm{N}$} & \multicolumn{3}{|c|}{ SKALA } & & \multirow[t]{2}{*}{ MEAN } \\
\hline & & & 1 & 2 & 3 & 4 & \\
\hline 14 & $\begin{array}{l}\text { Kecuali jika saya melakukan sesuatu yang } \\
\text { menarik, bahkan berbahaya, saya merasa } \\
\text { setengah mati dan membosankan }\end{array}$ & 150 & 73 & 43 & 31 & 3 & 1,76 \\
\hline 15 & $\begin{array}{l}\text { Butuh banyak perubahan dan variasi untuk } \\
\text { membuat saya benar-benar bahagia }\end{array}$ & 150 & 9 & 79 & 43 & 19 & 2,48 \\
\hline 16 & $\begin{array}{l}\text { Tampaknya hal yang sama dalam televisi } \\
\text { atau film sepanjang waktu, sungguh } \\
\text { membosankan }\end{array}$ & 150 & 25 & 82 & 26 & 17 & 2,23 \\
\hline 17 & $\begin{array}{l}\text { Ketika saya masih muda, saya sering berada } \\
\text { dalam situasi yang monoton dan } \\
\text { melelahkan }\end{array}$ & 150 & 16 & 79 & 45 & 10 & 2,32 \\
\hline 18 & $\begin{array}{l}\text { Di antara teman-teman saya, saya yang } \\
\text { terus melakukan sesuatu paling lambat }\end{array}$ & 150 & 66 & 46 & 23 & 15 & 1,91 \\
\hline
\end{tabular}

Pada tabel 4 akan disertakan tabel mean dengan dimensi extremely interested

Tabel 4. Jumlah data $(\mathrm{N})$, frekuensi extremely interested

\begin{tabular}{|c|c|c|c|c|c|c|c|}
\hline \multirow[t]{2}{*}{ NO. } & \multirow[t]{2}{*}{ INDIKATOR } & \multirow[t]{2}{*}{$\mathrm{N}$} & \multicolumn{3}{|c|}{ SKALA } & \multicolumn{2}{|r|}{$M E A N$} \\
\hline & & & 1 & 2 & 3 & 4 & \\
\hline 1 & $\begin{array}{l}\text { Mudah bagi saya untuk berkonsentrasi } \\
\text { pada aktivitas saya }\end{array}$ & 150 & 64 & 58 & 17 & 11 & 1,84 \\
\hline 2 & $\begin{array}{l}\text { Sepanjang waktu saya memproyeksikan } \\
\text { dalam pikiran saya tentang hal-hal yang } \\
\text { harus dilakukan }\end{array}$ & 150 & 24 & 78 & 23 & 2 & 1,87 \\
\hline 3 & $\begin{array}{l}\text { Saya merasa mudah untuk menghibur diri } \\
\text { sendiri }\end{array}$ & 150 & 24 & 61 & 52 & 13 & 2,36 \\
\hline 4 & $\begin{array}{l}\text { Saya mendapat banyak pujian dari apa } \\
\text { yang saya lakukan }\end{array}$ & 150 & 11 & 30 & 81 & 28 & 2,16 \\
\hline 5 & $\begin{array}{l}\text { Didalam kondisi apapun saya terbiasa } \\
\text { mencari sesuatu agar minat saya terjaga }\end{array}$ & 150 & 41 & 87 & 12 & 10 & 1,94 \\
\hline
\end{tabular}


Tabel 4. Jumlah data (N), frekuensi extremely interested (Lanjutan)

\begin{tabular}{|c|c|c|c|c|c|c|c|}
\hline \multirow[t]{2}{*}{ NO. } & \multirow[t]{2}{*}{ INDIKATOR } & \multirow[t]{2}{*}{$\mathrm{N}$} & \multicolumn{4}{|c|}{ SKALA } & \multirow[t]{2}{*}{$M E A N$} \\
\hline & & & 1 & & & 4 & \\
\hline 6 & Saya suka menunggu dengan sabar & 150 & 34 & 66 & 40 & 10 & 2,18 \\
\hline 7 & Saya sering terbangun dengan ide baru & 150 & 31 & 83 & 25 & 11 & 2,89 \\
\hline 8 & $\begin{array}{l}\text { Saya ingin melakukan hal-hal yang lebih } \\
\text { menantang dalam hidup }\end{array}$ & 150 & 46 & 64 & 36 & 4 & 1,99 \\
\hline 9 & $\begin{array}{l}\text { Banyak orang akan mengatakan bahwa } \\
\text { saya orang yang kreatif atau imajinatif }\end{array}$ & 150 & 64 & 49 & 34 & 3 & 1,84 \\
\hline 10 & $\begin{array}{l}\text { Saya memiliki banyak minat, saya tidak } \\
\text { punya waktu untuk melakukan semuanya }\end{array}$ & 150 & 36 & 84 & 14 & 16 & 2,06 \\
\hline
\end{tabular}

Pada tabel 5 akan disertakan tabel mean dengan dimensi kepercayaan terhadap diri sendiri.

Tabel 5. Jumlah data (N), frekuensi kepercayaan terhadap diri sendiri

\begin{tabular}{|c|c|c|c|c|c|c|c|}
\hline \multirow[t]{2}{*}{ NO. } & \multirow[t]{2}{*}{ INDIKATOR } & \multirow[t]{2}{*}{$\mathrm{N}$} & \multicolumn{4}{|c|}{ SKALA } & \multirow[t]{2}{*}{$M E A N$} \\
\hline & & & 1 & 2 & 3 & 4 & \\
\hline 1 & $\begin{array}{l}\text { Saya percaya bahwa ketika saya membuat } \\
\text { kesalahan, saya dapat memperbaiki atas } \\
\text { kesalahan yang saya lakukan }\end{array}$ & 150 & 10 & 6 & 97 & 37 & 3,07 \\
\hline 2 & $\begin{array}{l}\text { Saya percaya bahwa cara terbaik untuk } \\
\text { menangani masalah adalah dengan tidak } \\
\text { memikirkan masalah tersebut }\end{array}$ & 150 & 23 & 70 & 45 & 12 & 2,03 \\
\hline 3 & $\begin{array}{l}\text { Saya percaya bahwa hidup saya ditentukan } \\
\text { oleh saya sendiri }\end{array}$ & 150 & 17 & 65 & 31 & 37 & 2,58 \\
\hline 4 & $\begin{array}{l}\text { Saya percaya bahwa saya tidak dapat } \\
\text { menentukan apa yang dapat terjadi dihidup } \\
\text { saya }\end{array}$ & 150 & 18 & 66 & 32 & 34 & 2,54 \\
\hline
\end{tabular}


Pada tabel 6 akan disertakan tabel mean dengan dimensi kepercayaan terhadap hasil usaha.

Tabel 6. Jumlah data $(\mathrm{N})$, frekuensi kepercayaan terhadap hasil usaha

\begin{tabular}{|c|c|c|c|c|c|c|c|}
\hline \multirow[t]{2}{*}{ NO. } & \multirow[t]{2}{*}{ INDIKATOR } & \multirow[t]{2}{*}{$\mathrm{N}$} & \multicolumn{4}{|c|}{ SKALA } & \multirow[t]{2}{*}{ MEAN } \\
\hline & & & 1 & 2 & 3 & 4 & \\
\hline 1 & $\begin{array}{l}\text { Ketika saya berusaha untuk melakukan } \\
\text { sesuatu, saya pasti mengalami kegagalan }\end{array}$ & 150 & 16 & 66 & 19 & 49 & 2,67 \\
\hline 2 & $\begin{array}{l}\text { Saya tidak percaya jika berusaha keras } \\
\text { dalam melakukan sesuatu akan } \\
\text { mendapatkan hasil yang baik }\end{array}$ & 150 & 12 & 16 & 79 & 43 & 3,02 \\
\hline 3 & $\begin{array}{l}\text { Saya percaya ketika saya berusaha, saya } \\
\text { akan mendapatkan hal yang saya inginkan }\end{array}$ & 150 & 1 & 17 & 73 & 59 & 3,26 \\
\hline 4 & $\begin{array}{l}\text { Saya merasa tidak ada gunanya mencoba } \\
\text { sesuatu hal karena saya percaya bahwa } \\
\text { saya tidak lebih pintar dari orang lain }\end{array}$ & 150 & 36 & 88 & 22 & 4 & 1,96 \\
\hline
\end{tabular}

Pada tabel 7 akan disertakan tabel mean dengan dimensi kepercayaan tentang adanya keberuntungan.

Tabel 7. Jumlah data $(\mathrm{N})$, frekuensi kepercayaan tentang adanya keberuntungan

\begin{tabular}{lllrrrrrr}
\hline NO. & INDIKATOR & N & \multicolumn{5}{c}{ SKALA } & MEAN \\
\cline { 3 - 8 } & & & 1 & 2 & 3 & 4 & 3,33 \\
\hline 1 & Saya percaya dengan keberuntungan & 150 & 5 & 17 & 51 & 77 & 2,68 \\
2 & $\begin{array}{l}\text { Saya percaya bahwa apa yang terjadi hari } \\
\text { ini adalah sesuatu yang tidak disengaja }\end{array}$ & 150 & 8 & 46 & 82 & 14 & 3,07 \\
3 & $\begin{array}{l}\text { Saya percaya lebih baik menjadi beruntung } \\
\text { daripada menjadi pintar }\end{array}$ & 150 & 9 & 37 & 38 & 66 &
\end{tabular}

Pada tabel 8 akan disertakan tabel mean dengan dimensi ketergantungan akan bantuan orang lain.

Tabel 8. Jumlah data (N), frekuensi ketergantungan akan bantuan orang lain

\begin{tabular}{|c|c|c|c|c|c|c|c|}
\hline \multirow[t]{2}{*}{ NO. } & \multirow[t]{2}{*}{ INDIKATOR } & \multirow[t]{2}{*}{$\mathrm{N}$} & \multicolumn{4}{|c|}{ SKALA } & \multirow[t]{2}{*}{$M E A N$} \\
\hline & & & 1 & 2 & 3 & 4 & \\
\hline 1 & $\begin{array}{l}\text { Saya adalah orang yang membutuhkan } \\
\text { bantuan orang lain ketika mengerjakan } \\
\text { sesuatu }\end{array}$ & 150 & 12 & 22 & 90 & 26 & 2,86 \\
\hline 2 & $\begin{array}{l}\text { Sebagian dari hidup saya dipengaruhi oleh } \\
\text { orang lain }\end{array}$ & 150 & 21 & 69 & 38 & 22 & 2,40 \\
\hline
\end{tabular}


Pada tabel 9 akan disertakan tabel mean dengan dimensi speeding langsung.

Tabel 9. Jumlah data (N), frekuensi speeding langsung

\begin{tabular}{|c|c|c|c|c|c|c|c|}
\hline \multirow[t]{2}{*}{ NO. } & \multirow[t]{2}{*}{ INDIKATOR } & \multirow[t]{2}{*}{$\mathrm{N}$} & \multicolumn{4}{|c|}{ SKALA } & \multirow[t]{2}{*}{$M E A N$} \\
\hline & & & 1 & 2 & 3 & 4 & \\
\hline 1 & $\begin{array}{l}\text { Saya sering mengemudi dengan kecepatan } \\
\text { tinggi ketika jalan sedang sepi }\end{array}$ & 150 & 4 & 22 & 34 & 90 & 3,4 \\
\hline 2 & $\begin{array}{l}\text { Saya tidak suka mengemudi dengan } \\
\text { kecepatan tinggi ketika melewati kawasan } \\
\text { permukiman }\end{array}$ & 150 & 68 & 34 & 30 & 18 & 2,00 \\
\hline
\end{tabular}

Pada tabel 10 akan disertakan tabel mean dengan dimensi speeding tak langsung.

Tabel 10. Jumlah data (N), frekuensi speeding tak langsung

\begin{tabular}{llllllll}
\hline NO. INDIKATOR & $\mathrm{N}$ & \multicolumn{4}{c}{ SKALA } & MEAN \\
\cline { 3 - 7 } & & & 1 & 2 & 3 & 4 \\
\hline 1 & $\begin{array}{l}\text { Saya tidak suka mengemudi dengan } \\
\text { kecepatan tinggi di tikungan }\end{array}$ & 150 & 64 & 38 & 31 & 17 & 2,06 \\
& $\begin{array}{l}\text { Saya mengemudi dengan kecepatan tinggi } \\
\text { ketika hujan }\end{array}$ & & & & & & 2,55 \\
\end{tabular}

Dari hasil data survey diatas dapat dilihat responden memiliki keinginan untuk mengemudi dengan kecepatan tinggi saat kondisi jalan sedang sepi. Setelah mengetahui hasil data survey, maka akan dilakukan analisis dengan menggunakan data yang telah terkumpul penuh menggunakan metode Structural Equation Modelling (SEM) dengan program AMOS. Berikut akan ditampilkan model SEM yang digunakan dan hasil koefisien jalur yang berguna untuk mengetahui seberapa besar hubungan antara boredom proneness dan locus of control terhadap pilihan kecepatan saat mengemudi. Gambar modifikasi dengan data keseluruhan dapat dilihat pada gambar 1 dibawah ini.

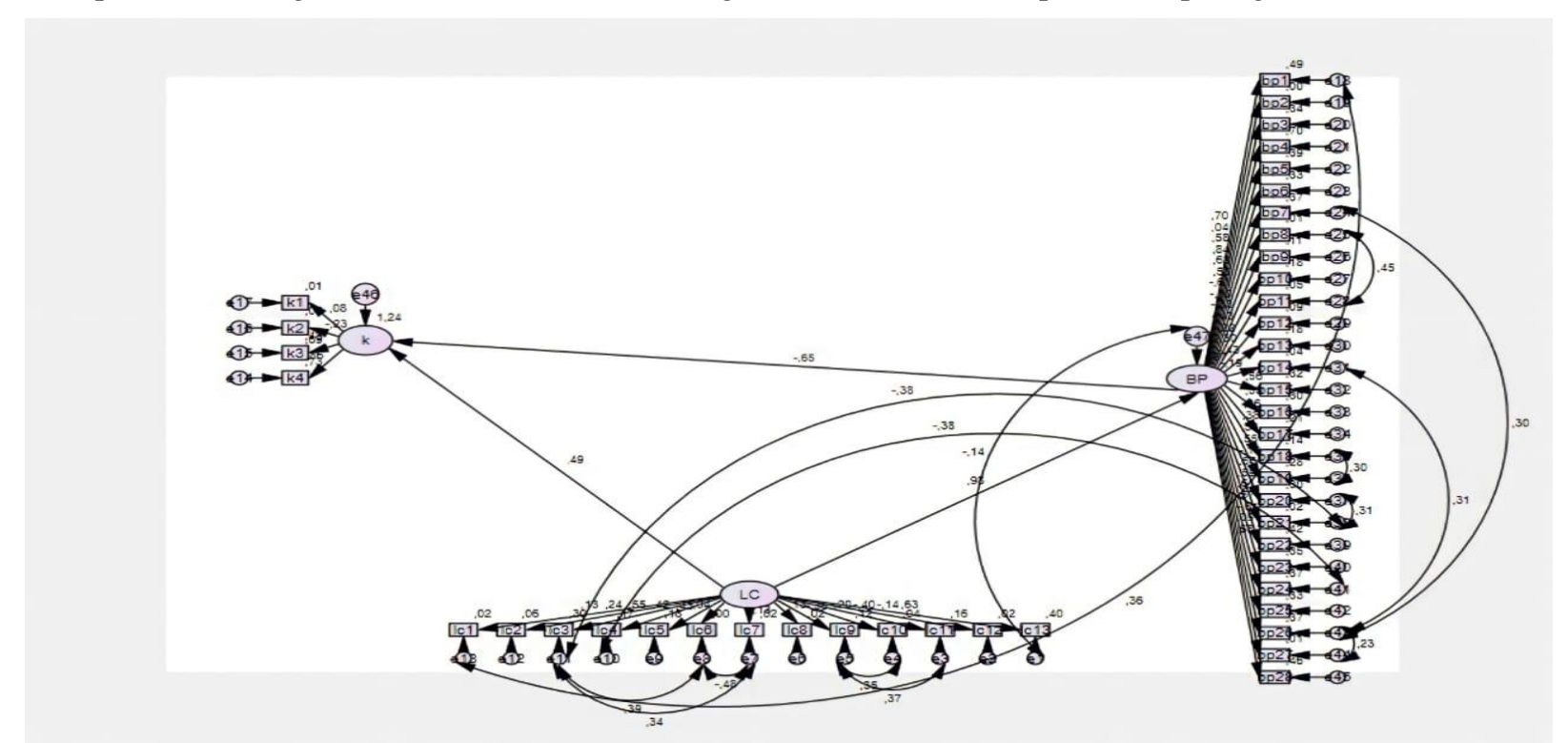

Gambar 1. Diagram modifikasi ke-1 dengan data keseluruhan 
Berdasarkan model modifikasi ke-1 pada gambar 1, setelah angka koefisien jalur dikuadratkan maka didapatkan kekuatan hubungan variabel locus of control terhadap boredom proneness sebesar $82,81 \%$. Untuk variabel boredom proneness mempengaruhi pilihan kecepatan pada saat mengemudi sebesar $-42,51 \%$ (responden yang memiliki kecenderungan boredom proneness tinggi akan berkecepatan rendah sedangkan responden yang memiliki kecenderungan boredom proneness rendah akan berkecepatan tinggi) dan untuk variabel locus of control berpengaruh sebesar $18,49 \%$ terhadap pilihan kecepatan saat mengemudi.

\section{KESIMPULAN DAN SARAN}

\section{Kesimpulan}

Kesimpulan yang didapat adalah sebagai berikut:

1. Berdasarkan data keseluruhan yang didapatkan dari metode SEM, locus of control mempengaruhi boredom proneness sebesar $82,81 \%$.

2. Berdasarkan data keseluruhan yang didapatkan dari metode SEM, boredom proneness mempengaruhi pilihan kecepatan saat mengemudi sebesar $-42,51 \%$. Tanda minus (-) dalam persen tersebut menunjukan bahwa hasil dari Metode SEM adalah hasil responden yang mempunyai tingkat boredom proneness yang rendah cenderung berkecepatan tinggi.

3. Berdasarkan data keseluruhan yang didapatkan dari metode SEM, locus of control mempengaruhi pilihan kecepatan saat mengemudi sebesar 18,49\%.

4. Berdasarkan dari data yang didapatkan dari kuesioner, responden memiliki kecenderungan untuk berkecepatan tinggi di jalan yang cenderung sedang sepi (rataan=3,4).

\section{Saran}

Saran yang diberikan adalah sebagai berikut:

1. Berdasarkan penelitian, dapat dilakukan intervensi kecepatan dalam bentuk sarana dan prasarana khususnya untuk jalan yang cenderung sepi, misalnya memasang speed bumper atau rambu batas kecepatan agar pengemudi tidak mengemudi dengan kecepatan tinggi.

2. Untuk pengemudi pria dan dewasa muda perlu adanya sosialisasi untuk mengurangi kecepatan khususnya untuk jalan yang cenderung sepi.

3. Melakukan penyebaran kuesioner secara langsung juga dikarenakan terdapat beberapa responden yang kurang memahami pertanyaan yang ada pada kuesioner online.

\section{DAFTAR PUSTAKA}

Bustan, M. N. “Epidemiologi Penyakit Tidak Menular. (Jakarta).”(2007).

Julianto, E.N. "Hubungan antara Kecepatan, Volume dan Kepadatan Lalu Lintas Ruas Jalan Siliwangi (Semarang).” Jurnal Teknik Sipil dan Perencanaan ,Vol.12, No.2 Juli 2010, hal: 151-160. (2010).

Kreitner and Kinicki. "Perilaku Organisasi. Edisi 5. (Jakarta).” (2004).

Nurliana, S., \& Supani, A. "Rancang Bangun Alat Pemberi Isyarat Kecepatan Maksimum Melalui SMS Gateway Berbasis Mikrokontroler Pada Helm”. TEKNIKA, 12(2), 21-28. (2018).

Rotter, J.B. "Generalized Expectancies for Internal VeRSUDs External Control of Reinforcement." Psychological Monographs, 80 (1, Whole No. 609). (1966).

Vodanovich, S. J. "The Essence of Boredom”. The Psychological record. 43: 3-12. (2016). 
